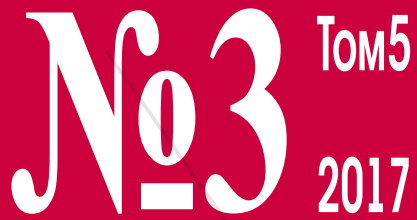

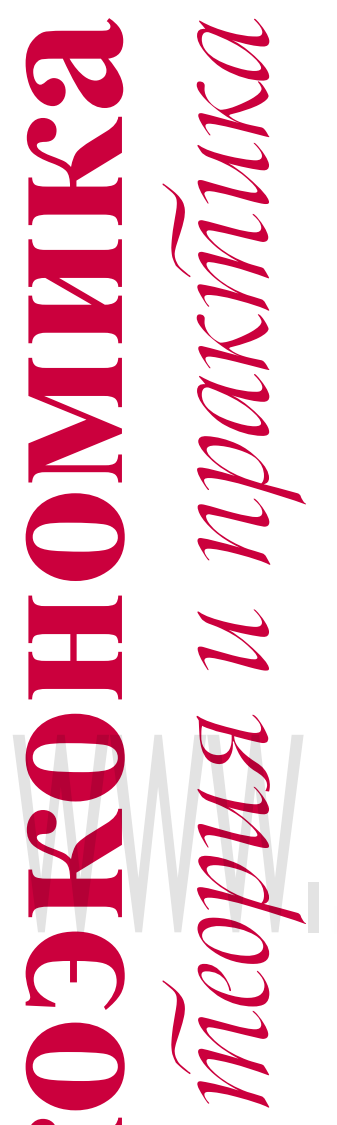

\section{Pharmacoeconomics theory and practice

口 КРИТЕРИИ ЭФФЕКТИВНОСТИ В ФАРМАКОЭКОНОМИЧЕСКОМ АНАЛИЗЕ

口 РЕЗУЛЬТАТЫ РОССИЙСКИХ ФАРМАКОЭКОНОМИЧЕСКИХ ИССЛЕДОВАНИЙ 


\title{
METHODOLOGY OF CONDUCTING AN EFFECTIVENESS ANALYSIS FOR THE TREATMENT OF ARTERIAL HYPERTENSION
}

\author{
Tolordava G.A.
}

\author{
Federal State Autonomous Educational Institution of Higher Education I.M. Sechenov First Moscow \\ State Medical University of the Ministry of Health of the Russian Federation (Sechenov University), \\ Moscow, Russia
}

\section{Summary:}

This article focuses on pharmacoeconomical analysis of effectiveness in the treatment of arterial hypertension(AH). This article describes the main stage of the effectiveness analysis which is information research, and the criteria for including publications in effectiveness analysis. The articles includes the rationale for using the effectiveness endpoints for this nosology, and the use of questionnaires for effectiveness analysis.

Keywords: arterial hypertension, cardiovascular diseases, effectiveness analysis, questionnaires, pharmacoeconomics.

\section{Introduction}

The scope of arterial hypertension is attributable to its widespread prevalence worldwide. Information from Russian and foreign epidemiological studies demonstrates that the prevalence of this nosology in different countries among the adult population of different age and social status ranges from $30 \%$ to $40 \%[5,16]$. Huge sums of money are spent on diagnosing arterial hypertension and its treatment, which is certainly a heavy burden for health budget [17].

Cardiovascular complications caused by arterial hypertension, such as myocardial infarction, heart failure, stroke and many others are the cause of the early incapacity and death of such patients, which is an additional financial damage for the health system $[1,2,10]$

\section{Effectiveness analysis}

The effectiveness analysis includes the selection of an indicator that accurately shows the effectiveness and usefulness of the studied treatment regimens. The correct choice of effectiveness criteria makes it possible to provide pharmacoeconomic "cost-effectiveness" analysis in subsequent phases [8].

Information research is an essential phase of effectiveness analysis. To find the largest number of information sources, the search should be done in Russian and foreign databases. The main sources of data about treatment of arterial hypertension for pharmacoeconomic analysis, are presented in Figure 1.

For conducting an informational research is necessary to define search criteria such as keywords that reveal the subject of the study. The results of the information research are: randomised clinical trial (RCT), pharmacoeconomic research, clinical recommendations, articles, questionnaire results, etc. The method of conducting the information search is presented in Figure 2.

Figure 2 demonstrates that the first selected publications require careful screening. Effectiveness levels should be determined according to scales of assessment of evidentiary levels and credibility. Most notably, studies with evidentiary levels A or B are selected: pieces of evidence that were summarized in the systematic review, in meta-analysis and ones, obtained in prospective RCTs, respectively. In the absence of these, studies with less evidentiary levels are considered for usage. The result of the screening is aggregation of publications that meet the criteria of the pharmacoeconomic analysis for further use.

It is necessary to select effectiveness criteria in the form of surrogate endpoints and final endpoints to evaluate the treatment of $\mathrm{AH}$, during an information search.

It should be noted that, with such nosology as $\mathrm{AH}$, surrogate endpoints reflecting the direct and indirect clinically significant effects of treatment,

\section{The three basic sources of data about treatment of arterial hypertension}

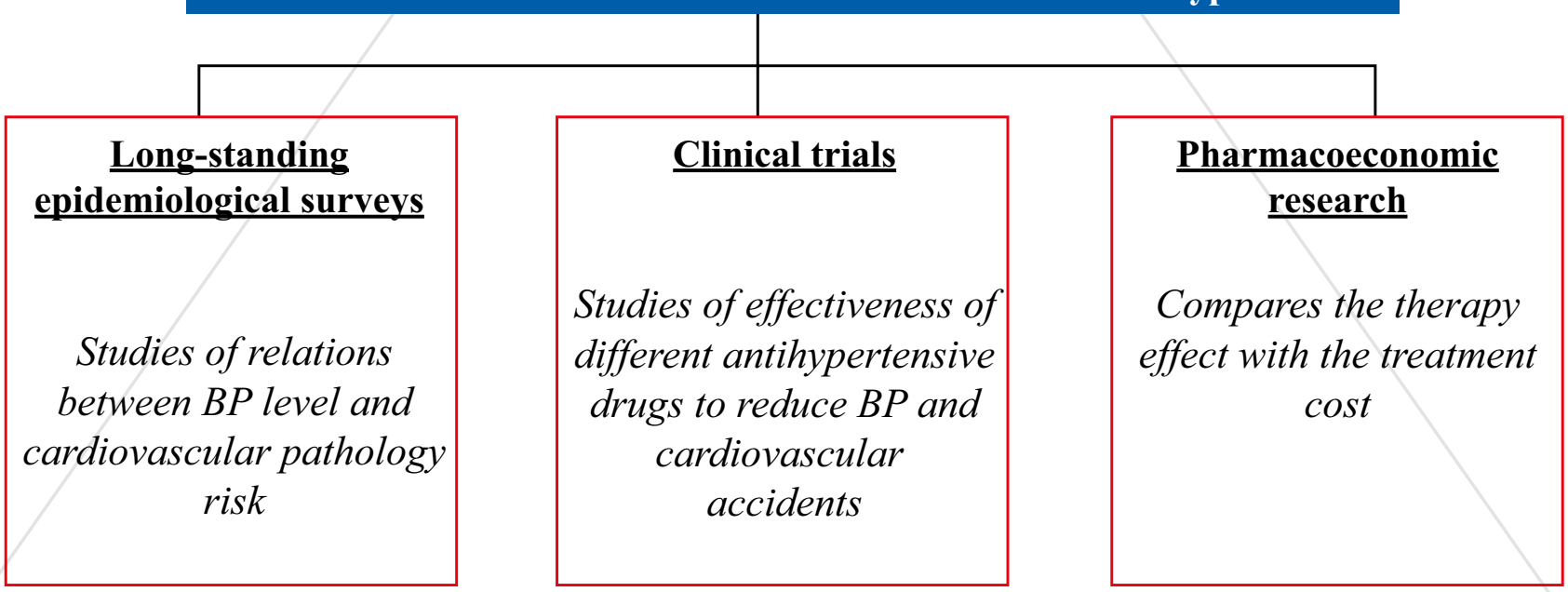

Figure 1. Main sources of data about treatment of arterial hypertension 


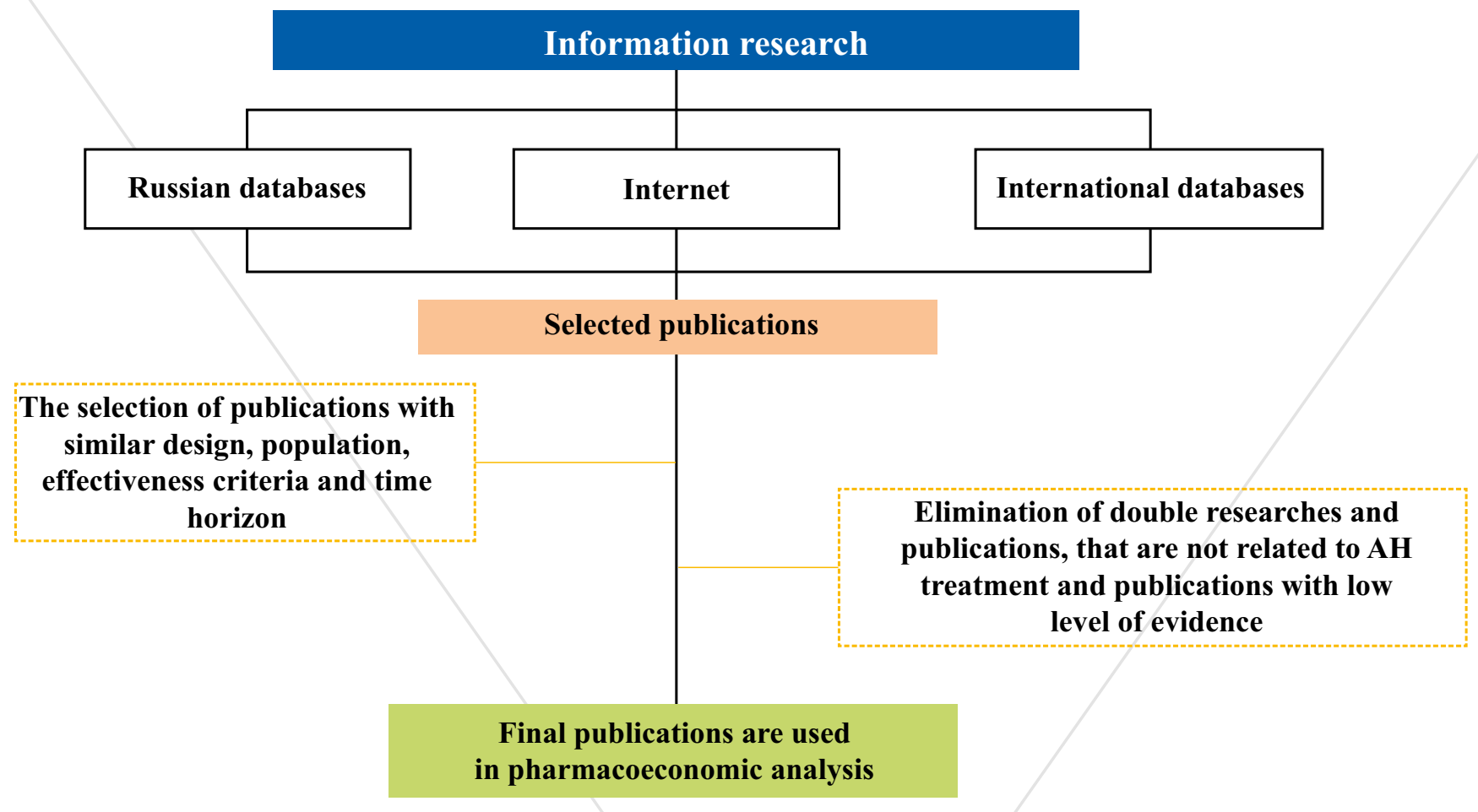

Figure 2. The method of conducting an information research

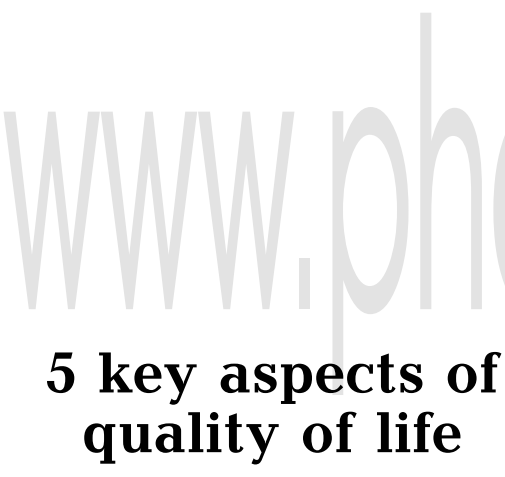
quality of life

\section{1) physical well-being}

\section{2) mental state}

\section{3) social functioning}

\section{4) role functioning}

\section{5) subjective perception of health}

Figure 3.5 main aspects of quality of life

which show the impact of the treatment scheme on the frequency of complications at $\mathrm{AH}$, play an important role in effectiveness evaluation. Direct clinical effects in the treatment of $\mathrm{AH}$ include the achievement of target numbers of blood pressure (BP) as the primary therapy purpose. The indirect events could be cardiovascular complications such as myocardial infarction, heart failure, etc., as well as undesired effects such as hypotension, coughing, etc. [9].

The following events can be used as survivability criteria: mortality and life year gained(LYG), as well as the addition of quality adjusted life year (QALY), and the results of questionnaires that characterize the efficacy of therapy in terms of quality of life (QL).

As for today, QL is one of the most important indicators of effectiveness evaluation, the main components of QL are presented in Figure $3[11,12]$.

In order to obtain good data in real clinical practice and to obtain reliable information about the efficacy of the prescribed therapy, the questionnaires are used as a standard tool for estimating the QL [13].

The studies in which the QL in case of $\mathrm{AH}$ are more than 30 years old. These studies use different questionnaires and scales for estimating quality of life[14, 15]. The most commonly used questionnaires to determine the QL for the patients with cardiovascular diseases are presented in Figure 4:

\section{Conclusion}

Thus, information research and its results play a special role in the effectiveness analysis. Surrogate endpoints reflecting direct and indirect clinically meaningful results of the treatment are important in evaluating the effectiveness of the treatment of AH. The article presents the basic questionnaires used in the evaluation of $L Q$ for treatment in patients with $A H$, the results of which can later be used as endpoints. 


\begin{tabular}{|c|c|}
\hline № & Questionnaire name \\
\hline 1 & Quality of Well-Being Index (QWBI) \\
\hline 2 & MHIQ \\
\hline 3 & Overall Quality of Life Scale \\
\hline 4 & Quality of Life Index \\
\hline 5 & EUROQOL - EuroQOL Group \\
\hline 6 & MOS-SF 36 \\
\hline 7 & Psychological General Well-Being Index \\
\hline 8 & Sickness Impact Profile \\
\hline 9 & Nottingham Health Profile \\
\hline 10 & HAD \\
\hline
\end{tabular}

Figure 4. Frequently used QL questionnaires for patients with cardiovascular diseases

\section{Bibliography:}

1. Diagnostics and treatment of arterial hypertension: Russian recommendations (fourth revision)//System hypertensions. 2010. No. 3. P. 5-26.

2. Karpov Yu.A. Treatment of cardiovascular disease patients: The role of the blockade of the renin-angiotensin system with Sartans//RMJ. 2009 Vol. 23. P. $1548-1554$

3. Clinical Pharmacology/Edited by V.G. Kukes. M.: GEOTAR-Media, 2013. $1056 \mathrm{p}$.

4. Clinical recommendations. Diagnosis and treatment of arterial hypertension. The Ministry of Health of the Russian Federation, Moscow 2013

5. Ministry of Health of the Russian Federation "diagnosis and treatment of arterial hypertension" clinical recommendations Moscow 2013

6. Ostroumova O.D., Maximov M.L. The place of angiotension-converting enzyme inhibitors in the treatment of arterial hypertension in different groups of patients//Cardiovascular therapy and prevention. 2010. No. 9 (7). P. 90-96.

7. Federal clinical recommendations on the use of the spirometry//Russian Respiratory Society, Moscow - 2013.

8. Yagudina R.I., Babiy V.V. Methodological bases for the analysis of medical technologies effectiveness in pharmacological research// Pharmacoeconomics: theory and practice. -2015. -Vol. 3, №1. P.7-11.

9. Tolordava G.A., Arinina E.E., Kulikov A.Yu. Pharmacoeconomical analysis of Fozinopril drug in the treatment of patients with arterial hypertension// Pharmacoeconomics: theory and practice. -2015. -Vol. 4, №1. P.70-78.

10. Makarova E.I., Tolordava G.A., Arinina E.E. Pharmacoeconomical analysis of Trombo ACC drug in the treatment of patients with cardiovascular diseases// Pharmacoeconomics: theory and practice. -2015. -Vol. 3, №4. P.69-74.

11. Khetagurova A.K. Quality of life issues in modern palliative medicine/A.K. Khetagurova//Issues. Manag. Healthcare. 2003. -Vol. 6 (13). -P. 49-50.

12. Stady protokol for the WHO project to develop a Quality of Life Assesswent instrument // Quality of Life Research . - 1993. - V. 2. - P. 153-158.

13. Translating health study questionnaires and evaluating them: the Quality of life a project approach. International of Quality of life assessment / M. Bullinger et al . // Clin . Epidemiol . -1998. - V.51 . - P. 913-923.

14. Health-Related Quality-of-Life measurement in Hypertension . A Review of randomized controlled drug trials / I.Cote , J.P. Gregorie , J.Moisan // Pharmacoeconomics . - 2000. - V. 18 (5). - P. 435-450.

15. Chesnokova I.V. An assessment of the quality of life in cases of arterial hypertension. /Chesnokova I.V., Konanykhina S.A.//VII Scientific and Practical Conference "Special project: scientific research analysis "(14-15 June 2012)

16. WHO//A global brief on Hypertension Silent killer, global public health crisis/ WHO 2013.2 [electronic source] URL http://www.who.int/cardiovascular_diseases/publications/global_brief_hypertension/ru/ (data extracted on April 4, 2017)

17. 2. O. D. Ostroumova, O. V. Bondarets, E. G. Sharikova. Treatment of hypertension: a comparison of clinical and economic effectiveness of original and generic drugs // Systemic hypertension. - 2008 №4 P.18-20 